\title{
Relações mãe-filho no contexto da prematuridade e a importância da enfermagem neonatal: revisão integrativa
}

\author{
Mother-child relations in the context of prematurity and the importance of neonatal nursing: \\ integrative review
}

Relaciones madre-hijo em el contexto de la prematurez y la importancia de la enfermería neonatal: revisíon integrativa

\section{Resumo}

Objetivo: identificar na literatura científica sentimentos e percepções evidenciados por mães de filhos prematuros internados na Unidade de Terapia Intensiva Neonatal acerca das interações com a equipe de enfermagem. Método: revisão integrativa realizada em novembro de 2020. Captaram-se estudos publicados integralmente entre 2015 - 2020 , indexados nas bases de dados MEDLINE, LILACS e BDENF, em português e inglês, submetidos à síntese qualitativa. Resultados: foram selecionados 14 artigos publicados em revistas nacionais e internacionais. A análise dos resultados, de forma descritiva, constituiu três categorias temáticas: Sentimentos ambíguos e dificuldades para concretizar a maternidade; Método canguru como estratégia significativa para vinculação afetiva mãe-filho e Acolhimento da equipe de enfermagem às famílias. Conclusão: O cuidado de enfermagem baseado na compreensão do outro, interação social, acolhimento e partilha das angústias das mães que têm seus recém-nascidos internados na Unidade de Terapia Intensiva Neonatal mostra a relevância de ações que promovam o vínculo afetivo entre mães e filhos.

Palavras-chave: Recém-nascido prematuro; Relações mãe-filho; Enfermagem neonatal; Unidades de Terapia Intensiva Neonatal; Revisão.

\begin{abstract}
Objective: to identify in the scientific literature feelings and perceptions evidenced by mothers of premature children admitted to the Neonatal Intensive Care Unit about interactions with the nursing staff. Method: integrative review conducted in November 2020. Studies published in full between 2015 - 2020 were captured, indexed in the MEDLINE, LILACS and BDENF databases, in Portuguese and English, submitted to qualitative synthesis. Results: 14 articles published in national and international magazines were selected. The analysis of the results, in a descriptive way, constituted three thematic categories: Ambiguous feelings and difficulties to realize motherhood; Kangaroo method as a significant strategy for affective bonding between mother and child and welcoming the nursing team to families. Conclusion: Nursing care based on understanding the other, social interaction, welcoming and sharing the anxieties
\end{abstract}


of mothers who have their newborns admitted to the Neonatal Intensive Care Unit shows the relevance of actions that promote the emotional bond between mothers and children.

Keywords: Infant premature; Neonatal nursing; Mother-child relationship; Intensive Care Units Neonatal; Review.

\section{Resumen}

Objetivo: identificar en la literatura científica los sentimientos y percepciones que evidencian las madres de niños prematuros ingresados en la Unidad de Cuidados Intensivos Neonatales sobre las interacciones con el personal del enfermería. Método: revisión integradora realizada en noviembre de 2020. Los estudios se publicaron íntegramente entre 2015 - 2020, indexados en las bases de datos MEDLINE, LILACS y BDENF, en portugués e inglés, presentados a síntesis cualitativa. Resultados: Se seleccionaron 14 artículos publicados en revistas nacionales e internacionales. El análisis de los resultados, de manera descriptiva, constituyó tres categorías temáticas: Sentimientos ambiguos y dificultades para realizar la maternidad; El método madre canguro como estrategia significativa para el vínculo afectivo entre madre e hijo y acogida del equipo de enfermería a las familias. Conclusión: El cuidado de enfermería basado en la comprensión del otro, la interacción social, acoger y compartir las ansiedades de las madres que tienen a sus recién nacidos ingresados en la Unidad de Cuidados Intensivos Neonatales muestra la relevancia de las acciones que promueven el vínculo emocional entre madres e hijos.

Palabras clave: Recién nacido prematuro; Enfermería neonatal; Relaciones madre-hijo; Unidades de Cuidado Intensivo Neonatal; Revisión.

\section{Introdução}

O nascimento de um bebê é uma ocasião única e especial para a maioria das famílias. A preparação para a chegada do recém-nascido $(\mathrm{RN})$ desde a confirmação da gestação e a ansiedade para o primeiro encontro com o mesmo desperta várias emoções nos pais (Luz et al, 2019; Carvalho, Mafra, Schultz, Schumacher \& Aires 2019). No entanto, nem sempre a gestação dura o tempo planejado e sua interrupção precoce se torna realidade para muitas famílias.

A prematuridade é definida como o nascimento antes da $37^{\mathrm{a}}$ semana de gestação e decorrente de variáveis que englobam as condições maternas, fetais ou específicas da gestação, conforme a Sociedade Brasileira de Pediatria - SBP (2017). A internação hospitalar se justifica pela imaturidade anátomo-fisiológica do $\mathrm{RN}$, que necessita adaptar-se à vida extrauterina precocemente (Medina et al, 2017). Para isso, os aparatos disponíveis nas Unidades de Terapia Intensiva Neonatais (UTIN), compostos por uma série de tecnologias, equipamentos, sons e expressões, embora possam ser assustadores e até sererm considerados agressivos, são significativos para a sobrevivência dos neonatos prematuros (Carvalho et al, 2019; Santos et al, 2018).

O ambiente de uma UTIN não costuma ser acolhedor aos pais que têm seus filhos internados, pois é configurado como um local de sentimentos ambíguos de esperança e de medo. O enfrentamento do medo real da morte de um filho ocorre frente às intercorrências e complicações que acometem os RN ao mesmo tempo os pais nutrem a esperança na sua recuperação, justamente pelo fato de ser o local mais apropriado para atender seu filho (Silva, Menezes, Cardoso \& França, 2016; SBP, 2017; Nascimento, Morais, Amorim \& Santos, 2020).

O parto prematuro suprime, principalmente, a preparação materna do final da gestação e altera as expectativas da mulher com relação à maternidade (Silva et al, 2016; Medina et al, 2017; Santos et al. 2018). A experiência de manter um contato restrito com o RN, cuja aparência física não condiz com as expectativas criadas, num território adverso e impessoal, com rotinas e regras rígidas. Interfere de forma negativa na concretização da maternidade bem como da paternidade, podendo causar sofrimento psicológico para mães e pais (Carvalho et al, 2019; Silva et al, 2016; Medina et al, 2017; Santos et al, 2018). Diante dessa situação, os pais se percebem incapazes de compreender e responder adequadamente às necessidades do filho, ainda que essa proximidade seja fundamental tanto para eles como para o RN (Carvalho et al, 2019; SBP, 2017).

As vivências da prematuridade impactam a família toda. Entretanto, comprometem especialmente o binômio mãe-filho, despertando na mulher sentimentos como culpa, medo, insegurança, incapacidade maternal e outras fragilidades que a façam questionar sua relação com o RN internado. Associar um neonato ao ambiente de uma unidade de cuidados intensivos agrava o estresse e o potencial risco de morte, sobrecarregando ainda mais a ansiedade materna (Leite et al, 2020). 
Além de RN prematuros surgem famílias prematuras. O vínculo afetivo entre pais, mães e filhos vai sendo construindo gradativamente e tem relação com as questões internas e externas de cada pessoa envolvida (Santos, Bortolin, Zanin \& Tabaczinski, 2020). O RN prematuro cujos pais estabelecem um vínculo afetivo precoce tende a construir futuramente relações sociais com mais facilidade (Carvalho et al, 2019; Medina et al, 2017). Para mães e pais, essa proximidade com o filho assegura mais confiança, estreita os laços afetivos e diminui a sensação de incapacidade parental, devendo ser estimulada o mais precocemente possível e ser interrompida somente quando for absolutamente necessário (Ahlqvist-Björkroth, Boukydis, Axelin \& Lehtonen, 2017). Nesse momento de internação, essa relação entre mãe, pai e filho acontecerá durante a realização das rotinas do setor e dos cuidados com o RN. Mães e pais, ao serem encorajados a participar da realização de alguns cuidados em conjunto com os profissionais da unidade, vão adquirindo conhecimentos acerca das particularidades do seu filho em razão da prematuridade (Leite et al, 2020).

O Método Canguru (MC) é apontado como uma das estratégias mais eficazes de estreitamento dos laços afetivos entre mães e seus bebês, favorecendo o progresso do amadurecimento anátomo-fisiológico, o maternar em ambiente hospitalar e a possibilidade de alta mais precocemente (Carvalho et al, 2019; Silva et al, 2016; Nascimento et al, 2020; Lopes, Oliveira, Pereira, Romeiro \& Carvalho, 2017). Destaca-se também que a figura paterna tanto na realização do MC quanto no processo de vinculação afetiva como importante, visto que o bem-estar emocional da família deve ser uma preocupação, pois afeta diretamente o bem estar do RN (Carvalho et al, 2019; Ahlqvist-Björkroth et al, 2017).

A inclusão das famílias na rotina da UTIN não é um processo fácil de ser estabelecido, principalmente quando o cuidado em uma unidade intensiva concentra a realização de uma série de procedimentos e técnicas especializadas, podendo ser intensificado pela dificuldade de alguns profissionais da equipe de enfermagem para tentar atender as demandas parentais (Costa, Sanfelice e Carmona, 2019; Leite et al, 2020). Na maioria das instituições, as mães ainda estão mais presentes do que os pais, especialmente por questões como o aleitamento materno e a incompatibilidade de horários entre a jornada laboral dos pais e os horários liberados para entrada do pai na UTIN. Essa é uma das considerações que merece ser revista sob outra ótica, ampliando a participação de mães e pais com o mínimo de restrições possível. Estudos destacam a relevância da equipe multiprofissional no apoio às famílias, proporcionando acolhimento e respeito às individualidades e limitações de seus RN, favorecendo a adaptação à prematuridade (Carvalho et al, 2019; Silva et al, 2016; Medina et al, 2017; Leite et al, 2020; SBP, 2017).

Humanizar o cuidado, embora seja uma normativa das Políticas Públicas de Saúde deve ser uma premissa. Cuidar uma vida humana não deve precisar de um protocolo para ser desenvolvido de forma sensível e acolhedora, sem deixar de ser científico e técnico, mesmo em uma UTIN, conforme destacam Costa et al (2019) e Silva, Hoffmann e Zacaron (2018). Dessa forma, quando chegar o momento da alta hospitalar a família, possivelmente, se sentirá mais segura para atender as necessidades do RN em casa quando, no decorrer da trajetória hospitalar, esteve mais perto, conquistando mais segurança e confiança (Carvalho et al, 2019, Ahlqvist-Björkroth et al, 2017, Costa et al, 2019).

Embora compreendendo a importância da participação paterna nesse processo de internação, esse estudo objetivou identificar, na literatura científica, os sentimentos e percepções evidenciados por mães que tem filhos prematuros internados em UTIN cerca da importância das interações com a equipe de enfermagem na vivência desse processo.

\section{Metodologia}

Trata-se de uma revisão integrativa de literatura. Para realizar uma análise ampla da literatura, com discussões sobre métodos e resultados das pesquisas, bem como avaliar a viabilidade de futuros estudos, foram seguidas algumas fases, a saber: 1) definição do tema; 2) formulação do objetivo da pesquisa e da questão norteadora; 3) busca na literatura e delimitação dos critérios de inclusão e exclusão dos estudos; 4) categorização dos estudos; 5) avaliação destes; 6) interpretação dos resultados; 7) apresentação da revisão (Mendes, Silveira \& Galvão 2008; Souza, Silva \& Carvalho, 2010). 
Para elaborar a questão de pesquisa, foi utilizada a estratégia População Interesse Contexto (PICO) que permite ao pesquisador localizar de modo mais preciso a melhor informação científica possível para atender seus questionamentos (Santos, Pimenta \& Nobre, 2007). Apresenta-se na Tabela 1 os componentes da questão de pesquisa desta revisão.

Tabela 1 - Definição da questão de pesquisa a partir da estratégia PICO. Rio Grande, RS, Brasil, 2020.

\begin{tabular}{|c|l|c|}
\hline Descrição & Abreviação & Componente da questão \\
\hline População & P & Mães de recém-nascidos prematuros internados em UTIN \\
\hline Intervenção & I & $\begin{array}{c}\text { Acolhimento oferecido pela equipe de enfermagem às famílias e RN } \\
\text { prematuros internados em UTIN }\end{array}$ \\
\hline Comparação & C & $\begin{array}{c}\text { Identificação da importância da equipe de enfermagem no } \\
\text { acolhimento às mães e RN prematuros }\end{array}$ \\
\hline Desfecho & O & $\begin{array}{c}\text { Melhora do relacionamento afetivo entre mãe-RN - equipe de } \\
\text { enfermagem na UTIN }\end{array}$ \\
\hline
\end{tabular}

Fonte: Autores.

Para guiar esta revisão, formulou-se a seguinte questão de pesquisa: Qual a relevância das interações entre a equipe de enfermagem e as mães de RN prematuros internados em UTIN durante a hospitalização dos seus filhos?

A síntese do processo de seleção dos estudos seguiu o modelo PRISMA (Preferred Reporting Items for Systematic Reviews and Meta-Analyses) (Moher, Liberati, Telzlaff \& Altman, 2009). Os descritores utilizados para a busca encontram-se registrados no Banco de Descritores em Ciências da Saúde (DeCS): Prematuro; Relações Mãe-Filho; Enfermagem Neonatal. Destaca-se a utilização dos operadores boleanos AND e OR. As palavras-chave "Neonatal nursing" and "Neonatal ICU” and “Mother-child relationship” or “Mother-infant relations”, identificados no Medical Subjects Headings (MESH).

A coleta dos dados foi efetivada em novembro de 2020. Os termos foram inseridos na plataforma BVS (Biblioteca Virtual de Saúde), tendo como resultado da busca 217 artigos distribuídos nas bases de dados: Medical Literature Analysis and Retrieval System Online (MEDLINE), Literatura Latino Americana e do Caribe em Ciências da Saúde (LILACS) e Base de dados de Enfermagem (BDENF).

Foi realizado o refinamento da seleção aplicando-se os critérios de inclusão. Inicialmente foram selecionados artigos publicados em português e inglês ( $\mathrm{n}=186)$, disponíveis na íntegra $(\mathrm{n}=81)$, publicados entre os anos de 2015 a 2020 (n=32). Foram excluídos estudos secundários, cartas ao editor, estudos de revisão, duplicados (foram considerados apenas uma vez) ou indisponíveis na íntegra de modo gratuito $(n=25)$.

Os 25 artigos foram submetidos a uma leitura dos resumos e, posteriormente, a avaliação do texto na íntegra. As pesquisas realizadas com profissionais da área da saúde não entraram na composição da amostragem, visto que a vivência profissional difere da vivência materna, sendo esse o objeto deste estudo. Após a aplicação dos critérios de inclusão e exclusão, obteve-se uma amostra final de 14 artigos. 
Figura 1 - Fluxograma de identificação do processo de seleção dos artigos para compor a revisão integrativa, adaptado a partir do modelo PRISMA. Rio Grande, RS, Brasil, 2020.

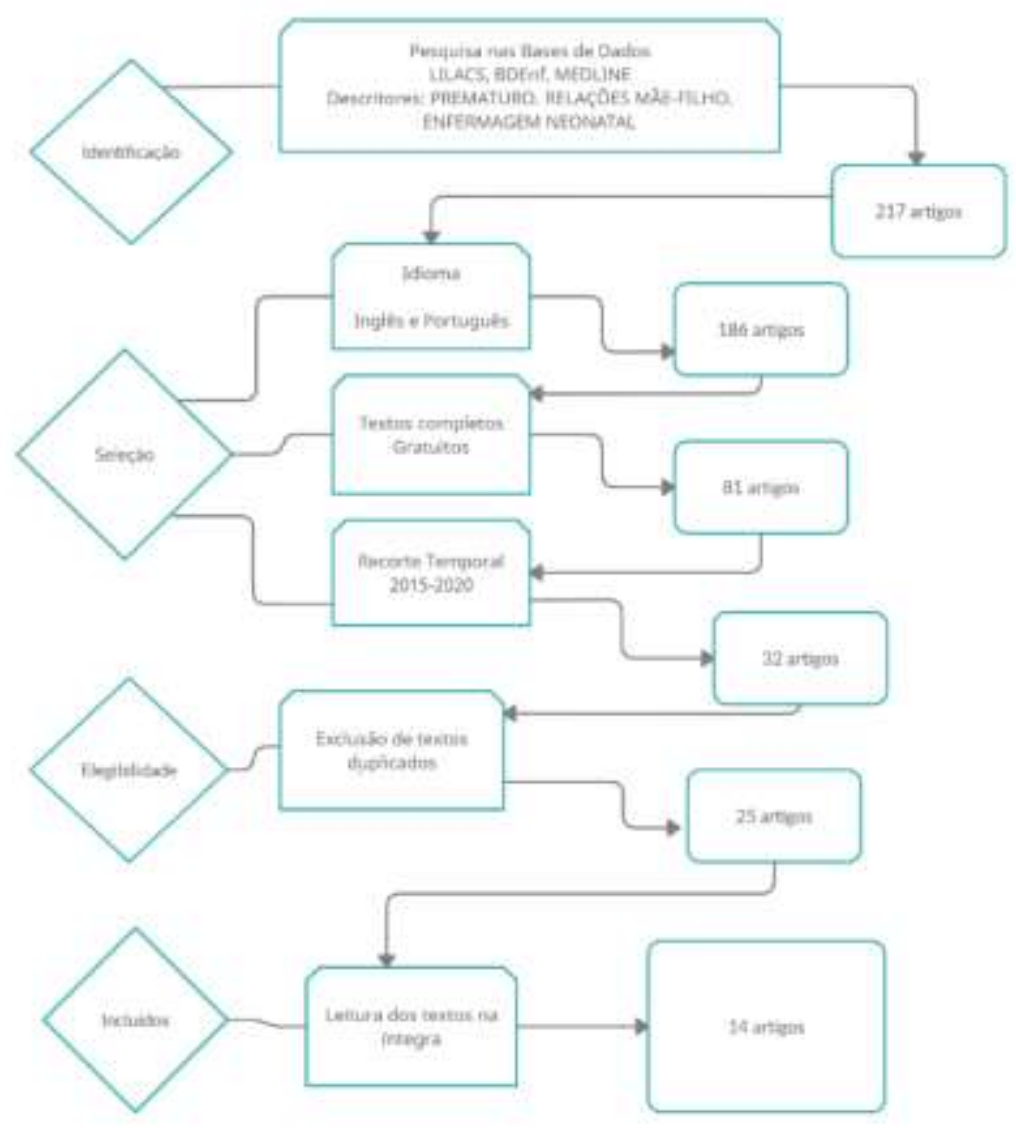

Fonte: Autores.

De acordo com Bardin (2016), a análise obedeceu três fases, a saber: pré-análise, exploração do material e interpretação dos resultados. Na primeira etapa, foi realizada uma pré-análise dos 14 artigos selecionados para essa revisão. Passaram por uma leitura flutuante, validando a pertinência dos mesmos. Nessa etapa, ainda, deu-se início a preparação do material e codificação inicial dos dados. Para análise dos dados dos estudos selecionados, foi utilizado o instrumento próprio, sendo considerada amostragem, local de realização da pesquisa, tipo de pesquisa desenvolvida, relevância dos achados, aproximação com a questão norteadora.

Na segunda fase, de exploração do material, foram realizadas várias leituras, extração dos códigos relevantes ao alcance do objetivo e agrupamento dos dados (Bardin, 2016). Cada artigo foi lido na íntegra, com foco nos resultados das pesquisas realizadas. Foi elaborada uma tabela na qual os achados relevantes para atender a questão norteadora foram evidenciados para cada estudo. Após, os achados foram agrupados de acordo com a similaridade existente entre eles, compondo grupos de informações.

Na terceira e última etapa da análise dos dados, a interpretação, esse agrupamento final foi avaliado e validado por todos os autores desse estudo (Bardin, 2016). Considerando-se os resultados significativos e assertivos para o alcance do objetivo proposto, a análise crítica e síntese qualitativa dos estudos selecionados, realizadas de forma descritiva, gerou três categorias: Sentimentos ambíguos e as dificuldades para concretizar a maternidade; Método Mãe Canguru como estratégia significativa para vinculação afetiva mãe-filho e Acolhimento da Equipe de Enfermagem às famílias e aos neonatos.

O nível de evidência utilizado para a classificação dos tipos de estudo foi definido conforme preconizado pelo Oxford 
Centre Evidence-Based Medicine: Nível I - Revisões sistemáticas e Metanálise de múltiplos estudos controlados; Nível II Revisão sistemática homogênea de estudos de coorte (com grupos de comparação e controle de variáveis), Estudo de coorte com pobre qualidade de randomização, controle ou sem acompanhamento longo, estudo de coorte transversal individuais; Resultados de pesquisas (observação de resultados terapêuticos ou evolução clínica); Nível III - estudos quase experimentais; Revisão sistemática homogênea de estudos de caso com grupo-controle, Estudos de caso com grupo-controle; Nível IV - Estudos não experimentais, Relatos de caso e série sem definição de caso controle; Nível V - dados de avaliação de programas e dados obtidos de forma sistemática, Opinião de autoridades respeitadas ou especialistas. Revisão da literatura não sistemática (ex: revisões integrativas, revisões narrativas, estudos teórico-reflexivos) (OCFEM, 2009).

\section{Resultados}

$\mathrm{Na}$ amostra foi possível identificar que o número de artigos sobre o objeto de estudo foi maior nos anos de 2016, com a seleção de cinco artigos, seguido do ano de 2015 com três artigos, apresentando um possível decréscimo na divulgação de pesquisas acerca do assunto nos últimos anos. Dessa forma foram selecionados apenas dois estudos nos anos de 2017, 2018, e apenas um estudo em 2019 e um em 2020. Os estudos realizados no Brasil correspondem a maior parte dos achados. Foram 10 pesquisas, significando um esforço dos pesquisadores em avaliar e melhorar a qualidade da assistência oferecida aos neonatos.

A base de dados com maior número de artigos selecionados foi a BDEnf com 10 artigos, sendo que sete deles constavam simultaneamente na plataforma LILACS. Outros quatro artigos foram localizados na MEDLINE. Apenas um dos artigos estava disponível nas três bases de dados simultaneamente. O idioma predominante nas pesquisas foi o português (10 artigos), seguido pelo inglês (quatro artigos). Prevaleceu o caráter qualitativo dos estudos sendo a entrevista o método mais utilizado para a coleta dos dados. A análise de conteúdo foi o principal método de escolha para tratamento dos dados obtidos nas pesquisas cujos resultados entraram nessa revisão. Em 13 das 14 pesquisas, a equipe de enfermagem foi mencionada pelos pais como parte fundamental das estratégias de enfrentamento à prematuridade e internação hospitalar dos seus filhos, reforçando a importância desses profissionais.

Os estudos selecionados foram identificados de forma alfanumérica de A1 a A14, conforme apresentados na Tabela 2.

Tabela 2 - Estudos selecionados para a amostra final de Revisão Integrativa de Literatura. Rio Grande, RS, Brasil, 2020.

\begin{tabular}{|c|c|c|c|c|c|c|c|c|c|}
\hline $\begin{array}{c}\mathrm{N}^{\circ} \\
\text { Artigo }\end{array}$ & $\begin{array}{c}\text { Base de } \\
\text { Dados }\end{array}$ & Autores & Título do artigo & Objetivo & $\begin{array}{l}\text { Nível } \\
\text { de } \\
\text { Evidên } \\
\text { cia }\end{array}$ & Amostra & $\begin{array}{l}\text { Coleta dos } \\
\text { Dados }\end{array}$ & $\begin{array}{c}\text { Análise } \\
\text { dos Dados }\end{array}$ & Local \\
\hline A1 & $\begin{array}{l}\text { LILACS } \\
\text { BDENF }\end{array}$ & $\begin{array}{l}\text { Cecagno, D } \\
\text { et al }(2020)\end{array}$ & $\begin{array}{l}\text { A vivência em uma } \\
\text { unidade de terapia } \\
\text { intensiva neonatal: um } \\
\text { olhar expresso pelas mães }\end{array}$ & $\begin{array}{l}\text { conhecer a vivência das mães de } \\
\text { bebês prematuros durante a } \\
\text { hospitalização em unidade de } \\
\text { terapia intensiva neonatal }\end{array}$ & 5 & 5 mães & $\begin{array}{l}\text { Entrevista } \\
\text { semi- } \\
\text { estruturada }\end{array}$ & $\begin{array}{l}\text { Análise } \\
\text { Temática }\end{array}$ & Pelotas \\
\hline $\mathrm{A} 2$ & BDENF & $\begin{array}{l}\text { Nzareth, IV } \\
\text { et al (2019) }\end{array}$ & $\begin{array}{l}\text { Riscos gestacionais e o } \\
\text { nascimento prematuro: } \\
\text { enfrentamento para a } \\
\text { maternagem }\end{array}$ & $\begin{array}{l}\text { compreender a vivência para a } \\
\text { maternagem após o parto } \\
\text { prematuro. }\end{array}$ & 5 & 12 mães & $\begin{array}{l}\text { Questionári } \\
\text { o } \\
\text { sociocultur } \\
\text { al de } \\
\text { Leininger + } \\
\text { Narrativa } \\
\text { de vida } \\
\end{array}$ & $\begin{array}{c}\text { Etnoenferm } \\
\text { agem }\end{array}$ & $\begin{array}{l}\text { Rio de } \\
\text { Janeiro }\end{array}$ \\
\hline A3 & $\begin{array}{l}\text { MEDLI } \\
\text { NE }\end{array}$ & $\begin{array}{l}\text { Wilson, C } \\
\& \text { Cook, C } \\
(2018)\end{array}$ & $\begin{array}{l}\text { Ambiguous loss and post- } \\
\text { traumatic growth: } \\
\text { Experiences of mothers } \\
\text { whose school-aged } \\
\text { children were born } \\
\text { extremely prematurely }\end{array}$ & $\begin{array}{l}\text { desenvolver uma visão sobre as } \\
\text { experiências de mães cujos } \\
\text { filhos em idade escolar } \\
\text { nasceram prematuramente. }\end{array}$ & 5 & 9 mães & $\begin{array}{l}\text { Entrevista } \\
\text { semi- } \\
\text { estruturada }\end{array}$ & $\begin{array}{c}\text { Análise } \\
\text { Temática }\end{array}$ & $\begin{array}{c}\text { Nova } \\
\text { Zelândia }\end{array}$ \\
\hline A4 & BDENF & $\begin{array}{l}\text { Lelis, BDB } \\
\text { et al (2018) }\end{array}$ & $\begin{array}{l}\text { Acolhimento materno no } \\
\text { contexto da } \\
\text { prematuridade }\end{array}$ & $\begin{array}{l}\text { analisar o acolhimento às mães } \\
\text { de recém-nascidos pré-termo } \\
\text { (RNPT) hospitalizados nos } \\
\text { ambientes de cuidados de um } \\
\text { Hospital Amigo da Criança }\end{array}$ & 5 & 8 mães & $\begin{array}{l}\text { Entrevista } \\
\text { semi- } \\
\text { estruturada }\end{array}$ & $\begin{array}{l}\text { Análise } \\
\text { Temática } \\
\text { de } \\
\text { Conteúdo }\end{array}$ & $\begin{array}{l}\text { Minas } \\
\text { Gerais }\end{array}$ \\
\hline
\end{tabular}




\begin{tabular}{|c|c|c|c|c|c|c|c|c|c|}
\hline A5 & BDENF & $\begin{array}{l}\text { Zani, AV \& } \\
\text { Alvim, HC } \\
(2017)\end{array}$ & $\begin{array}{l}\mathrm{O} \text { filho prematuro de } \\
\text { baixo peso: a maternagem } \\
\text { hospitalizada }\end{array}$ & $\begin{array}{l}\text { analisar as vivências maternas } \\
\text { frente à hospitalização do filho } \\
\text { prematuro de muito baixo peso. }\end{array}$ & 5 & 12 mães & Entrevista & $\begin{array}{l}\text { Discurso do } \\
\text { Sujeito } \\
\text { Coletivo }\end{array}$ & Londrina \\
\hline A6 & $\begin{array}{l}\text { LILACS } \\
\text { BDENF } \\
\text { MEDLI } \\
\text { NE }\end{array}$ & $\begin{array}{l}\text { Veronez, M } \\
\text { et al (2017) }\end{array}$ & $\begin{array}{l}\text { Vivência de mães de } \\
\text { bebês prematuros do } \\
\text { nascimento a alta: notas } \\
\text { de diários de campo }\end{array}$ & $\begin{array}{l}\text { descrever } \text { o processo de } \\
\text { construção do cuidar materno } \\
\text { mediado pelo enfermeiro } \\
\text { durante o período de internação } \\
\text { e alta de bebês prematuros. }\end{array}$ & 5 & 7 mães & $\begin{array}{c}\text { Pesquisa } \\
\text { Convergent } \\
\mathrm{e} \\
\text { Assistencial }\end{array}$ & $\begin{array}{l}\text { Análise } \\
\text { Temática } \\
\text { de } \\
\text { Conteúdo }\end{array}$ & Maringá \\
\hline A7 & $\begin{array}{l}\text { LILACS } \\
\text { BDENF }\end{array}$ & $\begin{array}{l}\text { Araújo, } \\
\text { AMG et al } \\
(2016)\end{array}$ & $\begin{array}{l}\text { A experiência do método } \\
\text { canguru vivenciada pelas } \\
\text { mães em uma } \\
\text { maternidade pública de } \\
\text { Maceió/Al Brasil }\end{array}$ & $\begin{array}{l}\text { relatar a experiência vivenciada } \\
\text { pelas mães inseridas no método } \\
\text { canguru em uma maternidade } \\
\text { pública. }\end{array}$ & 5 & 10 mães & Entrevistas & $\begin{array}{l}\text { Análise de } \\
\text { Conteúdo }\end{array}$ & Maceió \\
\hline A8 & $\begin{array}{l}\text { MEDLI } \\
\text { NE }\end{array}$ & $\begin{array}{l}\text { Jones, L et } \\
\text { al (2016) }\end{array}$ & $\begin{array}{l}\text { The Influence of } \\
\text { Neonatal Nursery Design } \\
\text { on Mothers' Interactions } \\
\text { in the Nursery. }\end{array}$ & $\begin{array}{l}\text { examinar a influência do design } \\
\text { do berçário neonatal nas } \\
\text { interações entre os enfermeiros } \\
\text { e mães de bebês no berçário. }\end{array}$ & 5 & $\begin{array}{l}66 \text { mães }(26 \\
\text { em } \\
\text { enfermaria } \\
\text { coletiva e } \\
40 \text { em sala } \\
\text { familiar } \\
\text { reservada) }\end{array}$ & $\begin{array}{l}\text { Entrevista } \\
\text { semi- } \\
\text { estruturada }\end{array}$ & $\begin{array}{l}\text { Estudo } \\
\text { Prospectivo } \\
\text { + Análise } \\
\text { Temática }\end{array}$ & Austrália \\
\hline A9 & $\begin{array}{l}\text { MEDLI } \\
\text { NE }\end{array}$ & $\begin{array}{l}\text { CHO, ES et } \\
\text { al }(2016)\end{array}$ & $\begin{array}{l}\text { The Effects of Kangaroo } \\
\text { Care in the Neonatal } \\
\text { Intensive Care Unit on the } \\
\text { Physiological Functions } \\
\text { of Preterm Infants, } \\
\text { Maternal-Infant } \\
\text { Attachment, and Maternal } \\
\text { Stress }\end{array}$ & 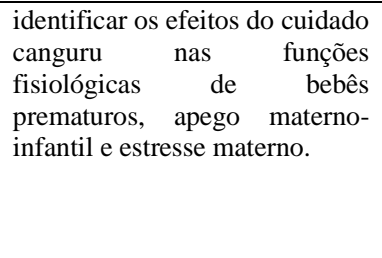 & 5 & $\begin{array}{l}40 \text { mães }(20 \\
\text { do Grupo } \\
\text { experiment } \\
\text { al e } 20 \text { do } \\
\text { Grupo } \\
\text { controle) }\end{array}$ & $\begin{array}{l}\text { Observação } \\
\text { direta e } \\
\text { monitorame } \\
\text { nto }\end{array}$ & $\begin{array}{l}\text { Teste T, } \\
\text { ANOVA de } \\
\text { medidas } \\
\text { repetidas e } \\
\text { teste } \\
\text { ANCOVA }\end{array}$ & Corea \\
\hline A10 & $\begin{array}{l}\text { LILACS } \\
\text { BDENF }\end{array}$ & $\begin{array}{l}\text { Magalhães, } \\
\text { SS et al } \\
(2016)\end{array}$ & $\begin{array}{l}\text { Sentimentos maternos, } \\
\text { favorecimento de vínculo } \\
\text { com bebês e aproximação } \\
\text { com o cuidado }\end{array}$ & $\begin{array}{l}\text { compreender os sentimentos } \\
\text { maternos, estabelecimento do } \\
\text { vínculo e participação da mãe } \\
\text { no cuidado ao filho em unidade } \\
\text { neonatal }\end{array}$ & 5 & 20 mães & $\begin{array}{c}\text { Observação } \\
\text { participante } \\
+ \text { Grupos } \\
\text { educativos }\end{array}$ & $\begin{array}{l}\text { Análise de } \\
\text { Conteúdo }\end{array}$ & Ceará \\
\hline A11 & $\begin{array}{l}\text { MEDLI } \\
\text { NE }\end{array}$ & $\begin{array}{l}\text { Brooks, JL } \\
\text { et al (2016) }\end{array}$ & $\begin{array}{l}\text { Birthing and Parenting a } \\
\text { Premature Infant in a } \\
\text { Cultural Context }\end{array}$ & $\begin{array}{l}\text { explorar as percepções das mães } \\
\text { Lumbee (maior tribo de índios } \\
\text { americanos a leste do rio } \\
\text { Mississippi) sobre ra } \\
\text { parentalidade de seus bebês } \\
\text { prematuros durante o primeiro } \\
\text { ano de vida no contexto de sua } \\
\text { cultura, incluindo o nascimento } \\
\text { e hospitalização de seus filhos. }\end{array}$ & 5 & 17 mães & $\begin{array}{l}\text { Entrevista } \\
\text { semi- } \\
\text { estruturada }\end{array}$ & $\begin{array}{l}\text { Análise de } \\
\text { Conteúdo }\end{array}$ & $\begin{array}{l}\text { Carolina } \\
\text { do Norte }\end{array}$ \\
\hline A12 & $\begin{array}{l}\text { LILACS } \\
\text { BDENF }\end{array}$ & $\begin{array}{l}\text { Tronco, CS } \\
\text { et al }(2015)\end{array}$ & $\begin{array}{l}\text { Manutenção da lactação } \\
\text { de recém-nascido pré- } \\
\text { termo: rotina assistencial, } \\
\text { relação mãe-filho e apoio }\end{array}$ & $\begin{array}{l}\text { compreender o significado da } \\
\text { permanência do recém-nascido } \\
\text { pré-termo na Unidade de } \\
\text { Terapia Intensiva Neonatal após } \\
\text { a alta hospitalar da mãe. }\end{array}$ & 5 & 7 mães & $\begin{array}{c}\text { Entrevista } \\
\text { fenomenoló } \\
\text { gica }\end{array}$ & $\begin{array}{c}\text { Método } \\
\text { Heideggeri } \\
\text { ano: análise } \\
\text { compreensi } \\
\text { va e análise } \\
\text { interpretati } \\
\text { va }\end{array}$ & $\begin{array}{c}\text { Rio Grande } \\
\text { do Sul }\end{array}$ \\
\hline A13 & $\begin{array}{l}\text { LILACS } \\
\text { BDENF }\end{array}$ & $\begin{array}{l}\text { Barroso, } \\
\text { ML et al } \\
(2015)\end{array}$ & $\begin{array}{lr}\text { Consequências } & \text { da } \\
\text { prematuridade } & \text { no } \\
\text { estabelecimento } & \text { do } \\
\text { vínculo afetivo entre mãe } \\
\text { adolescente e recém- } \\
\text { nascido }\end{array}$ & $\begin{array}{l}\text { apreender sob percepção } \\
\text { materna as consequências da } \\
\text { prematuridade } \\
\text { estabelecimento do vónculo } \\
\text { afetivo mãe adolescente/bebê } \\
\text { prematuro. }\end{array}$ & 5 & 10 mães & $\begin{array}{l}\text { Entrevista + } \\
\text { Observação } \\
\text { livre }\end{array}$ & $\begin{array}{l}\text { Análise de } \\
\text { Conteúdo }\end{array}$ & Fortaleza \\
\hline A14 & $\begin{array}{l}\text { LILACS } \\
\text { BDENF }\end{array}$ & $\begin{array}{l}\text { Oliveira, } \\
\text { MC et al } \\
(2015)\end{array}$ & $\begin{array}{lr}\text { Método } & \text { canguru: } \\
\text { percepções das mães que } \\
\text { vivenciam a segunda } \\
\text { etapa }\end{array}$ & $\begin{array}{l}\text { conhecer as percepções das } \\
\text { mães de recém-nascidos pré- } \\
\text { termo e/ou baixo peso sobre a } \\
\text { segunda etapa do Método } \\
\text { Canguru. }\end{array}$ & 5 & 5 mães & $\begin{array}{l}\text { Entrevista } \\
\text { semi- } \\
\text { estruturada }\end{array}$ & $\begin{array}{l}\text { Análise de } \\
\text { Conteúdo }\end{array}$ & $\begin{array}{c}\text { Rio Grande } \\
\text { do Sul }\end{array}$ \\
\hline
\end{tabular}

Fonte: Autores.

Os estudos incluídos nesta revisão foram classificados em três categorias temáticas: Sentimentos ambíguos e as dificuldades de concretização da maternidade; Método Canguru como estratégia eficaz de vinculação afetiva e Acolhimento da Equipe de Enfermagem às famílias. 
Tabela 3 - Categorias Temáticas, Estudos relacionados e Principais achados. Rio Grande, RS, Brasil, 2020.

\begin{tabular}{|c|c|c|}
\hline Categorias Temáticas & Estudos relacionados & Principais Achados \\
\hline $\begin{array}{l}\text { Sentimentos ambíguos e as } \\
\text { dificuldades na concretização } \\
\text { da maternidade }\end{array}$ & $\begin{array}{c}\text { A1,A2, A3, A4, A5, A6, } \\
\text { A9, A10, A11, A12, A13, } \\
\text { A14 }\end{array}$ & $\begin{array}{l}\text { Medo real da perda do filho X Esperança na recuperação do filho } \\
\text { por estar na UTIN } \\
\text { Dificuldade de se perceber mãe X Sentir-se mãe ao ver as } \\
\text { primeiras reações do filho } \\
\text { Impacto da prematuridade na vida da família X Construção de } \\
\text { uma rede de apoio com outras mães } \\
\text { Gratidão pela vida do filho X Desconstrução de expectativas } \\
\text { sobre outras gestações }\end{array}$ \\
\hline $\begin{array}{l}\text { Método Canguru como } \\
\text { estratégia de vinculação afetiva }\end{array}$ & $\mathrm{A} 2, \mathrm{~A} 4, \mathrm{~A} 7, \mathrm{~A} 9, \mathrm{~A} 14$ & $\begin{array}{l}\text { Vontade de realizar os cuidados com o filho } \\
\text { Dúvidas sobre sua capacidade de cuidar do filho } \\
\text { Sensação prazerosa de aconchegar o filho no colo } \\
\text { Sensação de incapacidade de aconchegar o filho }\end{array}$ \\
\hline $\begin{array}{l}\text { Acolhimento da Equipe de } \\
\text { Enfermagem às famílias }\end{array}$ & $\begin{array}{c}\mathrm{A} 1, \mathrm{~A} 2, \mathrm{~A} 3, \mathrm{~A} 4, \mathrm{~A} 6, \mathrm{~A} 7, \\
\mathrm{~A} 8, \mathrm{~A} 9, \mathrm{~A} 10, \mathrm{~A} 11, \mathrm{~A} 12, \\
\mathrm{~A} 13, \mathrm{~A} 14\end{array}$ & $\begin{array}{l}\text { Mãe como coadjuvante nos cuidados com o filho na UTIN } \\
\text { Importância de conhecer a equipe da UTIN ainda no Centro } \\
\text { Obstétrico } \\
\text { Escuta atenta da equipe de enfermagem na primeira visita } \\
\text { Desconstruir rigor na informação de normas e rotinas da unidade } \\
\text { Alta hospitalar pode ser mais traumática que o parto } \\
\text { Sensação de desamparo e medo da incapacidade de ser mãe sem } \\
\text { o apoio dos profissionais }\end{array}$ \\
\hline
\end{tabular}

Fonte: Autores.

\section{Discussão}

A hospitalização de um filho prematuro em UTIN quebra o simbolismo tradicional do nascimento. A interrupção precoce da gestação marca, para as famílias, o início de uma jornada sem prazo definido, com pouca possibilidade de planejamento, um período em que muitas certezas deixam de existir. A prematuridade pode ser considerada como uma situação carregada de significados e significações, sendo uma experiência subjetiva. Considerando essa subjetividade do ser mãe de prematuro, um dos questionamentos recai sobre a capacidade materna para cuidar do neonato, visto que o RN prematuro necessita dos cuidados da equipe de saúde antes do aconchego materno.

Em uma UTIN, não é aconselhável planejar um cuidado direcionado apenas ao neonato internado, mas sim contextualizar o cuidado abrangendo também a família. As maiores necessidades das famílias que tem um RN internado em UTIN estão relacionadas à segurança, suporte, informação e proximidade.

\subsection{Sentimentos ambíguos e as dificuldades na concretização da maternidade}

O primeiro encontro entre a mãe e o filho é emocionante e significativo. Se tornar mãe (ou pai) exige um movimento não só por parte dos pais, mas também da criança. Esse vínculo, considerado fundamental para a construção da parentalidade, vai sendo formado por meio de uma relação em que um influencia a resposta do outro. Quando se pensa na situação das mães e dos pais que têm seus RN internados em uma UTIN, pode-se imaginar o quão difícil se torna a formação do vínculo afetivo.

A maioria das participantes dos estudos A3, A5, A6, A11, A13 e A14 enfatizou que mesmo diante do trauma e da ruptura, ainda assim, sentia-se grata por terem seus filhos. Apesar do medo real da perda e das possíveis sequelas relativas à prematuridade, sentiram-se esperançosos na recuperação, considerando o contexto tecnológico e profissional presentes nas UTIN. A fé e a espiritualidade auxiliam a suportar esse período de hospitalização, como apresentaram os estudos A4, A11, A12, e A13.

A sensação de impotência materna é evidenciada quando relatado que a melhora dos RN é decorrente da qualidade da assistência de saúde ofertada. Até conseguir reconhecer a sua importância na vida dos filhos, muitas mulheres não se sentem confortáveis no papel de mãe dos neonatos prematuros. Destacaram-se como mais relevantes as ações de comunicação de informações relativas ao comportamento do $\mathrm{RN}$ e aos procedimentos e equipamentos utilizados além de uma escuta atenta às 
dúvidas e anseios maternos. Oportunizar às mães o contato físico e participação em algumas decisões relativas aos cuidados com o filho, desenvolvendo gradativamente a confiança dessas mães na equipe de enfermagem também foram destacadas como importantes.

Vários estudos - A1, A2, A3, A4, AA6, A8, A10, A12 e A14- apresentaram a necessidade das mães de conversar, compartilhar seus sentimentos com relação à internação hospitalar de seus filhos como forma de amenizar seu sofrimento. Conforme estudo de Silva, Cavalcante, Lucio, Rodrigues e Freitas (2021), o cuidado de enfermagem deve integrar o paciente, mas também seus familiares, considerando o contexto em que ele está inserido. De acordo com a pesquisa realizada por Utrilla Rojo, Séllan Soto, Ramos Cruz e Mateo Martinez (2018) na Espanha, tanto os pais quanto o neonato internado estão sob os cuidados da equipe de enfermagem. Entretanto, os recém-nascidos são o núcleo do cuidado.

Ao perceberem as primeiras reações dos RN à sua presença, fala e toque faz com que, aos poucos, a culpa e a sensação de fracasso vá dando lugar a uma sensação de importância na recuperação dos filhos. O entendimento dessa afeição entre eles faz com que a mãe deixe de se relacionar com um RN frágil e prematuro para ter um relacionamento com seu filho, de acordo com os estudos A6, A7, A9, A12, A13 e A14.

O nascimento é um momento em que pai, mãe e bebê estarão entrando em novo contexto, descobrindo e definindo seus papéis familiares. Porém, quando esse momento é vivenciado dentro de uma UTIN esses sujeitos são privados dessa contextualização e acabam adquirindo um papel secundário diante das necessidades do filho e da importância da atuação da equipe de saúde, em especial, da equipe de enfermagem. A presença dos pais na unidade acompanhando a vivência da internação do filho promove a aproximação com a equipe de enfermagem que cuida do neonato, aumentando a sensação de segurança e confiança nos profissionais. Além disso, promove nos pais uma familiarização de termos técnicos associados à saúde do paciente e maior conhecimento das reais condições de saúde do seu filho, de acordo com as pesquisas de Silva et al (2021) e de Sousa, Montenegro, Goveia, Corrêa, Rocha e Manzo (2017).

A internação de um filho em UTIN causa um impacto também nas relações sociais e familiares, pois especialmente a mãe passa a ter uma nova rotina, que inclui horas dentro de um hospital. Para estar próxima ao filho, prioriza acompanhar o RN ao invés dos outros filhos, se abstém da rotina doméstica, profissional e do convívio familiar. Cria-se, então, dentro do espaço hospitalar, conforme apontado nas pesquisas A3, A6, A11 e A13, uma rede de apoio e amizade com outras mães que vivenciam a mesma experiência e compreendem suas angústias.

A percepção da fragilidade dos filhos, intensificada pela aparência física impactante, é observada nos relatos dos estudos A6, A7, A9, A11, A13 como uma das dificuldades para a concretização da maternidade. Outro fator abordado consiste no medo de tocar um bebê tão pequeno e suscetível a infecções, que se encontra ligado a sondas, tubos e aparelhos com funções desconhecidas a ponto de desencadear o receio do apego e estabelecimento do vínculo a um bebê que pode morrer (Cecagno et al, 2020; Nazareth et al, 2019; Veronez, 2017; Brooks, 2015).

Por consequência, Cecagno (2020) destacam que também desconstroem algumas expectativas com relação aos filhos egressos da UTIN, visto que alguns poderão apresentar alguma particularidade no crescimento e desenvolvimento se comparados a RN a termo saudáveis. As mulheres que vivenciam a prematuridade de seus filhos, conforme Brooks (2016), passaram a refletir sobre um novo conceito do que significa ter qualidade de vida, pois crianças prematuras têm risco de apresentar atrasos cognitivos, deficiências sensoriais, problemas comportamentais e de aprendizagem, além do risco da dependência de algum tipo de tecnologia para se alimentar, respirar ou andar. Wilson e Cook (2018), obtiveram relatos maternos de que, a partir dessa experiência com a prematuridade de um filho, há nova perspectiva das mulheres com relação a planejar ou não uma nova gestação. 


\subsection{Método Canguru (MC) como estratégia significativa para vinculação afetiva mãe-filho}

A prematuridade coloca em xeque a capacidade materna da mulher. O RN prematuro possui particularidades, depende de cuidados profissionais antes do aconchego materno. A permanência das mães na UTIN e a possibilidade de realizar gradativamente os cuidados primários nos seus filhos oferece uma experiência ímpar de vinculação. Aos poucos, as mulheres vão assumindo e se apropriando desses cuidados que antes não eram realizados por medo de colocar a saúde do RN em risco. Esses eram realizados pela equipe de enfermagem em função da gravidade da situação.

$\mathrm{O} \mathrm{MC}$ foi considerado como uma estratégia importante de vinculação afetiva e empoderamento materno nas pesquisas A2, A4, A7, A9, A14. Os cuidados realizados no contexto hospitalar, sob supervisão e orientação profissional pode preparar essas mulheres para a continuidade dos cuidados pós-alta hospitalar (Nazareth, 2019). Além disso, é um momento de afetividade e relacionamento entre mãe e filho, permitindo o reconhecimento mútuo, além de promover uma melhor adaptação dos neonatos à procedimentos invasivos como a ventilação mecânica conforme achado no estudo de Souza et al (2017). Entretanto, algumas mães relataram que a sensação da obrigatoriedade da amamentação ou da coleta do leite reforçadas por comentários da equipe conferiram uma carga negativa a essa ação. Da mesma forma, na pesquisa A2, ressaltaram que a recusa para colocar o RN em posição canguru se dava em virtude da sensação de incapacidade de aconchegar um bebê tão pequeno e frágil.

O método deve iniciar ainda na UTIN, quando o RN apresentar condições clínicas que permitam a permanência por mais tempo no colo da mãe. Um estudo monitorou os sinais vitais dos bebês, evidenciando significativa melhora da frequência respiratória, dado que é um dos parâmetros avaliados para a oferta de dieta por via oral e início do estímulo ao aleitamento materno (Cho et al, 2016).

No momento da alta hospitalar, as mães ainda possuíam dúvidas sobre a capacidade de cuidar do próprio filho, o que foi considerado por algumas uma experiência mais traumática do que o parto prematuro, informado nas investigações A2, A3, A8, A12, A13 e A14. Estudos sinalizaram para a relevância de um programa de acompanhamento domiciliar composto por profissionais da equipe da UTIN por serem considerados de confiança das famílias (Wilson \& Cook, 2018; Zani \& Alvim, 2017). $\mathrm{O}$ estudo A5 tem falas das entrevistadas que evidenciam a importância da presença da equipe no ambiente domiciliar para o conhecimento da realidade e melhor preparação da família para receber o bebê após a alta hospitalar.

\subsection{Acolhimento da equipe de enfermagem às famílias}

O primeiro contato dos pais com um ambiente altamente tecnológico da UTIN tende a causar espanto, surpresa e gerar muitas dúvidas. É um momento de enfrentamento de uma realidade não planejada: a interrupção antecipada da gestação e a separação precoce entre pai, mãe e RN (Nazareth, 2019; Brooks, 2016). Estudo de Cecagno et al (2020), acerca da vivência de mães em uma UTIN mostrou que há necessidade dos pais serem informados adequadamente sobre a transferência de seus filhos para o setor e a gravidade do seu quadro clínico ainda no Centro Obstétrico. As mães relataram que se sentiam coadjuvantes no processo de cuidar de seus filhos, uma vez que os pais ou outro familiar foram os primeiros a receberem maiores informações.

Mais relevante do que informar sobre as normas e rotinas de funcionamento de uma UTIN, a equipe de enfermagem deve optar pela escuta reflexiva. No primeiro momento de interação com as famílias se faz necessário o favorecimento da fala do outro, de modo que consiga expressar suas dúvidas e incertezas a respeito do RN. A equipe, especialmente a de enfermagem, deve responder às dúvidas e anseios de maneira clara e concisa, proporcionando a interação do neonato com sua família, porém respeitando o tempo e a individualidade com que cada pessoa enfrenta essa primeira aproximação do bebê (Cecagno et al, 2020; Veronez, 2017).

A maneira como pais e mães reagem tem a ver com suas histórias de vida e o enfrentamento da situação demanda tempo e um acolhimento sensível da equipe, destacado nas investigações A1, A11 e A14. As maiores necessidades das famílias que tem um RN internado em UTIN estão relacionadas a conforto, segurança, suporte, informação e proximidade, conforme Cecagno 
et al (2020). Apesar da ênfase no cuidado humanizado, evidenciada por Cecagno et al (2020) e Lelis et al (2018), ainda há um longo caminho a ser percorrido na implementação de práticas efetivas, especialmente no contexto das UTIN.

Vários estudos apontaram para a importância dos pais serem acolhidos desde a primeira visita à UTIN - A1, A2, A3, A4, A6, A7, A8, A9, A11, A12, A13 e A14. Estudo A11, realizado com mães indígenas, corroborou para a importância do acolhimento. A maior queixa esteve relacionada ao desconhecimento da equipe multiprofissional com relação as suas origens. As entrevistadas relataram que suas concepções culturais foram ignoradas.

Já o estudo A14, com mães que vivenciaram o MC apresentou relatos sobre o impacto negativo da cobrança da equipe de enfermagem com relação à visitação. Destacou que todas as ações de enfermagem desenvolvidas no processo de aproximação dos filhos foram fundamentais para a sua vinculação afetiva com o RN. Kynoe, Fugelseth e Hansen (2020), realizaram um estudo com mães imigrantes e enfermeiras norueguesas buscando apreender como se dava a comunicação quando não há uma linguagem comum, considerando o crescente aumento, nas últimas décadas, de mães sem uma linguagem comum com os profissionais de saúde nas UTINs. Diferenças na língua materna afetam a comunicação, tornando importante a presença de um intérprete. A falta de uma linguagem comum entre a família e a equipe dificulta e limita verbalmente a comunicação e requer a adoção de estratégias de linguagem não verbal e observação para sinalizar o sucesso nas ações maternas.

Como limitação do estudo aponta-se que se buscou identificar os sentimentos e percepções das mães, reduzindo as inferências aos sentimentos e vivências dos pais de prematuros internados em UTIN. Os resultados que surgiram nesse estudo poderão estimular a realização de novas pesquisas nessa área. É possível que os resultados apontem boas estratégias promotoras de um cuidado mais acolhedor às famílias, oferecendo um suporte no fortalecimento dos laços afetivos entre mãe, pai e neonato, além da prepará-los para a vivência domiciliar após a alta.

\section{Considerações Finais}

As evidências científicas sobre os sentimentos e percepções evidenciados por mães que têm filhos prematuros internados na Unidade de Terapia Intensiva Neonatal acerca do acolhimento oferecido pela equipe de enfermagem apontou que, apesar de sentirem-se gratas pela vida de seus filhos, mas têm medo de perdê-los e das possíveis sequelas relativas à prematuridade. Sentem-se esperançosas na sua recuperação, mas apresentam sensação de impotência, culpa, fracasso e receio do apego e estabelecimento do vínculo com um RN que pode morrer. Com o tempo sentem-se importantes na recuperação dos filhos, mas dificuldades para a concretização da maternidade.

Evidenciou-se que o MC uma estratégia significativa para vinculação afetiva mãe-filho, podendo auxiliar a prepará-las para a continuidade dos cuidados pós-alta hospitalar. Além disso, é um momento de afetividade e relacionamento entre mãe e filho, permitindo o reconhecimento mútuo entre eles. Propicia significativa melhora da frequência respiratória do RN, início da dieta por via oral e do estímulo ao aleitamento materno.

Quanto à importância do acolhimento da equipe de enfermagem às famílias as mães referiram a necessidade de serem informadas adequadamente sobre a transferência de seus filhos para a UTIN e a gravidade do seu quadro clínico, sendo importante serem acolhidas desde a primeira visita no setor. Necessitam escuta reflexiva com o favorecimento da fala de forma que consigam expressar suas dúvidas e incertezas a respeito do RN; resposta às suas dúvidas e anseios; interação com o neonato; conforto, segurança, suporte, informação e proximidade.

O cuidado de enfermagem baseado na compreensão do outro, na interação social, no acolhimento, na partilha das angústias das mães que têm seus RN internados na UTIN mostra a grande relevância de ações que promovam o vínculo afetivo entre elas e seus filhos. As ações de cuidado realizadas com os RN e seus familiares poderão tornar a experiência de internação neonatal menos sofrida, especialmente no que se refere à formação de um vínculo afetivo saudável. A percepção da presença dos pais nesse ambiente como um elemento do cuidado, pode abrir caminho para se pensar novas estratégias de cuidar na UTIN, 
proporcionando o aprimoramento profissional e também pessoal dos sujeitos envolvidos nesse processo.

\section{Referências}

Ahlqvist-Björkroth, S., Boukydis, Z., Axelin, A. M., \& Lehtonen, L. (2017). Close Collaboration with Parents ${ }^{\mathrm{TM}}$ intervention to improve parents' psychological well-being and child development: Description of the intervention and study protocol. Behavioural Brain Research, 325(B), 303-310. 10.1016/j.bbr.2016.10.020

Araujo, A. M. G., Melo, L. S., Souza, M. E. D. C. A., Freitas, M. M. S. M., Lima, M. G. L., \& Lessa, R. O. (2016). A experiência do método canguru vivenciada pelas mães em uma maternidade pública de Maceió/Al. Rev. iberoam. educ. investi. Enferm, 6(3), 19-29. https://www.enfermeria 21.com/revistas/aladefe/articulo/210/a-experiencia-do-metodo-cangur u-vivenciada-pelas-maes-em-uma-maternidade-pulica-de-maceioal-brasil/

Bardin, L.. (2016). Análise de Conteúdo.: Edições 70. 123-132.

Barroso, M. L., Pontes, A. L., \& Rolim, K. M. C. (2015). Consequências da prematuridade no estabelecimento do vínculo afetivo entre mãe adolescente e recém-nascido. Rev Rene, 16(2), 168-75. 10.15253/2175-6783.2015000200005

Brooks, J. L., Holdtich-Davis, D., Docherti, S. L., Theodorou, C. S. (2016). Birthing and Parenting a Premature Infant in a Cultural Context. Qual Health Res. 26(3):87-398. 10.1177/1049732315573205

Carvalho, E., Mafra, P. P. O. C., Schultz, L. F., Schumacher, B., \& Aires, L. C. P. (2019). Inclusão e participação nos cuidados ao filho pré-termo na unidade neonatal: percepções paternas. Rev Enferm UFSM, 9(31), 1-19. 10.5902/2179769231121

Cecagno D., Fröhlinch C. V. C., Cecagno S., WeyKamp J. M., Biana C. B., \& Soares, M. C. (2020). A vivência em uma unidade de terapia intensiva neonatal: um olhar expresso pelas mães. Rev Fun Care Online, 12, 566-572. http://dx.doi.org/0.9789/2175-5361.rpcfo.v12.8827.

Cho, E. S., Kim, S. J., Kwon, M. S., Cho, H., Kim, E. H., Jum, E. M., \& Lee, S. (2016). The Effects of Kangaroo Care in the Neonatal Intensive Care Unit on the Physiological Functions of Preterm Infants, Maternal-Infant Attachment, and Maternal Stress. J Pediatr Nurs, 31(4), 430-8. 10.1016/j.pedn.2016.02.007

Costa, J. V. S., Sanfelice, C. F. O., \& Carmona, EV. (2019). Humanização da assistência neonatal na ótica dos profissionais da enfermagem. Rev enferm UFPE on line, 13, e242642. 10.5205/1981-8963.2019.242642

Jones, L., Peters, K., Rowe, J., \& Sheeran, N. (2016). The Influence of Neonatal Nursery Design on Mothers' Interactions in the Nursery. J Pediatr Nurs, 31, e301-12. 10.1016/j.pedn.2016.05.005

Kynoe, N.M., Fugelseth, D., Hansen, I. (2020). When a common language is missing: Nursing-mother communication in the NICU. A qualitative study. J Clin Nurs, 29, 2221-2230. http://doi.org/10.1111/jocn.15212

Leite, P. I. A. G., Pereira, F. G., Demarchi, R. F., Hattori, T. Y., Nascimento, V. F., Terças-Trettel, A. C. P. (2020). Humanização da assistência de enfermagem em Unidade de Terapia Intensiva Neonatal. Revista Enf Health Care, 9(1), 90-102. 10.18554/reas.v9i1.3649

Lelis, B. D. B., Souza, M. I., Mello, D. F., Wernt, M., Velozo, A. B. F., Leite, A. M. (2018). Acolhimento materno no contexto da prematuridade. Rev enferm UFPE on line, 12(6), 1563-9. 10.5205/1981-8963-v12i6a230763p1563-1569-2018

Lopes, T. R. G., Oliveira, S. S., Pereira, I. R. B. O., Romeiro, I. M. M., \& Carvalho, J. B. L. (2017). Humanização dos cuidados ao recém-nascido no Método Canguru: relato de experiência. Rev enferm UFPE on line, 11(11), 4492-7. 10.5205/reuol.23542-49901-1-ED.1111201727

Luz, R. T., Trindade, T. B. S., Lima, D. S., Climaco, L. C. C, Ferraz, I. S., Teixeira, S. C. R., \& Silva, R. R. (2019). Importância da presença de familiares durante o internamento neonatal. Rev enferm UFPE on line, 13, e239790. https://doi.org/10.5205/1981-8963.2019.239790

Magalhães, S. S., Queiroz, M. V. O., \& Brasil, E. G. M. (2016). Sentimentos maternos, favorecimento de vínculo com bebês e aproximação com o cuidado. Cienc Cuid Saude, 15(2), 227-234. 10.4025/cienccuidsaude.v15i1.24727

Medina, I. M. F., Granero-Molina, J., Fernández-Sola, C., Hernández-Padilla, J. M., Ávila, M. C., \& López-Rodríguez, M. M. (2017). Bonding in neonatal intensive care units: Experiences of extremely preterm infants' mothers. Women Birth, 31(4), 325-330. https://doi.org/10.1016/j.wombi.2017.11.008

Mendes. K. D. S., Silveira, R. C. C. P., \& Galvão, C. M. (2008). Revisão integrativa: método de pesquisa para a incorporação de evidências na saúde e na enfermagem. Texto Contexto Enferm, 17(4), 758-764. Recuperado de http://www.scielo.br/pdf/tce/v17n4/18.pdf

Moher, D., Liberati, A., Tetzlaff, J., \& Altman, D. G. (2009). PRISMA Group. Preferred reporting items for systematic reviews and meta-analyses: the PRISMA Statement. PLoS Med, 6(7), e1000097. 10.7326/0003-4819-151-4-200908180-00135.

Nascimento, A. C. S. T., Morais, A. C., Amorim, R. C., \& Santos, D. V. (2020) The care provided by the family to the premature newborn: analysis under Leininger's Transcultural Theory. Rev Bras Enferm, 73(Suppl 4), e20190644. 10.1590/0034-7167-2019-0644

Nazareth, I. V., Santos, I. M. M., Silva, L. R., Moraes, S. R. L., \& Silva, I. R. (2019). Riscos gestacionais e o nascimento prematuro: enfrentamento para a maternagem. Rev enferm UFPE on line, 13(4), 1030-9. 10.5205/1981-8963-v13i04a237875p1030-1039-2019

Oliveira, M. C., Locks, M. O. H., Girond, J. B. R., \& Costa, R.. (2015). Kangaroo method: perceptions of mothers who experience the second stage. J. res.: fundam. care. online, 7(3), 2939-2948. 10.9789/2175-5361.2015.v7i3.2939-2948

Oxford Centre for Evidence-Based Medicine (OCFEM). (2009). Levels of evidence: http://www.cebm.net/oxfordcentre-evidence-based-medicine-levelsevidencemarch-2009/.

Santos, C.M. C., Pimenta, C. A. M., \& Nobre, M. R. C. (2007) A estratégia pico para a construção da pergunta de pesquisa e busca de evidências. Rev Latinoam Enfermagem, 15(3). http://www.scielo.br/pdf/rlae/v15n3/pt_v15n3a23.pdf 
Santos, M., Bortolin, D., Zanin, S. C. G., \& Tabaczinski, C. (2020). Impacto da prematuridade na constelação da maternidade. Psicologia E Saúde Em Debate, 6(2), 246-259. 10.22289/2446-922X.V6N2A16

Santos, M. C., Gomes, G. C., Hirsch, C. D., Nerenberg, P. K. O., Oliveira, A. M. N., \& Nobre, C. M. G. (2018). Vivências de mães junto ao recém-nascido na Unidade de Terapia Intensiva Neonatal. Cienc Cuid Saude, 17(4), e27984. 10.4025/cienccuidsaude.v17i4.45164

Silva, E. M., Cavalcante, L. S., Lucio, I. M. L., Rodrigues, I. A., \& Freitas, A. S. F. (2021). Percepção da família quanto aos cuidados de enfermagem em uma Unidade de Terapia Intensiva Neonatal. Research, Society and Development, 10(11), e262101119597. https://doi.org/10.33448/rsd-v10i11.19597

Silva, A. R., Hoffmann, E., \& Zacaron, S. S. (2018). O acolhimento na unidade de terapia intensiva neonatal: percepção usuários(as) e profissionais. Argumentum, 10(1), 198-212. 10.18315/argumentum.v10i1.18739

Silva, R. M. M., Menezes, C. C. S., Cardoso, L. L., \& França, A. F. O. (2016) Vivências de famílias de neonatos prematuros hospitalizados em unidade de terapia intensiva neonatal: revisão integrativa. Rev Enf Cent. O. Min, 6(2), 2258-2270. http://www.seer.ufsj.edu.br/index.php/recom/article/view/940/1108

Sociedade Brasileira de Pediatria (SBP). (2017) Em documento científico, SBP alerta para medidas que podem reduzir os riscos à vida e à saúde dos bebês prematuros. http://www.sbp.com.br/imprensa/detalhe/nid/em-documento-cientifico-sbp-alerta-para-medidas-que-podem-reduzir-os-riscos-a-vida-e-a-saudedos-bebes-prematuros-1/

Sousa, F. C. P., Montenegro, L. C., Goveia, V. R., Corrêa, A. R., Rocha, P. K., \& Manzo, B. F. (2017). A participação da família na segurança do paciente em unidades neonatais na perspectiva do enfermeiro. Texto Contexto, 26(3), e1180016 https://doi.org/10.1590/0104-07072017001180016

Souza, M. T., Silva, M. D., Carvalho, R. (2010). Revisão integrativa: o que é e como fazer. Einstein, 8(1 Pt1), 102-6. https://www.scielo.br/j/eins/a/ZQTBkVJZqcWrTT34cXLjtBx/?format=pdf\&lang=pt

Tronco, C. S., Padoim, S. M. M., Paula, C. C., Rodrigues, A. P., Neves, E. T., \& Weimann, A. R. M. (2015). Manutenção da lactação de recém-nascido prétermo: rotina assistencial, relação mãe-filho e apoio. Esc Anna Nery, 19(4), 635-640. 10.5935/1414-8145.20150085

Utrilla Rojo, A., Sellán Soto, M., Ramos Cruz, A., \& Mateo Martínez, G. (2019). La relación enfermera - padres - neonato desde la perspectiva enfermera. Revista Cubana de Enfermería, 34(3). http://www.revenfermeria.sld.cu/index.php/enf/article/view/2402

Veronez, M., Borghesan, N. A. B., Correa, D. A. M., \& Higarashi, I. H. (2017). Vivência de mães de bebês prematuros do nascimento a alta: notas de diários de campo. Rev Gaúcha Enferm, 38(2), e60911. http://www.scielo.br/pdf/rgenf/v38n2/0102-6933-rgenf-1983-144720170260911.pdf

Wilson, C., \& Cook, C. (2018). Ambiguous loss and post-traumatic growth: Experiences of mothers whose school-aged children were born extremely prematurely. J Clin Nurs, 27(7-8), e1627-39. 10.1111/jocn.14319.

Zani, A. V. \& Alvim, H. C. (2017). O filho prematuro de baixo peso: a maternagem hospitalizada. Rev enferm UFPE online, 11(4), 1724-30. 10.5205/reuol.10438-93070-1-RV.1104sup201715 